\title{
An Examination of the Impact of Participation in a Conversation Group for Individuals with a Closed Head Injury
}

\author{
Glenn Goldblum, Marna Mulder and Alexandra von Gruenewaldt
}

\author{
Department of Communication Pathology, \\ University of Pretoria
}

\begin{abstract}
This study describes the impact of participation in a conversational group for individuals with chronic closed head injury in the Department of Communication Pathology at the University of Pretoria over the period 1995-2000. The information was obtained through a combination of clinical observations by the writers; the examination of data from Pragmatic measures; and a Quality of Life Scale that was compiled and administered (to both the subjects and their significant others) examining the perceived effects of group therapy over time. The results showed that despite the plateauing of pragmatic competence over time, the impact of group therapy appeared to reveal itself in perceived improvements in social-communicative competence and quality of life by the subjects. Recommendation and suggestions were made for the refinement of the QOL Scale to more reliably measure the subjective perceptions of group members regarding the perceived value of group therapy. In addition to addressing future implications to move the conversation group forward, the results of the current study lead the authors to advocate the establishment of conversation groups for individuals with CHI who are suitable candidates.
\end{abstract}

\section{INTRODUCTION}

\author{
"What I was, I am not. \\ What I was I am never going to be again." \\ (Campbell-Korves, 1991, p.3)
}

The dawning of the new millennium is a worthy time to examine the process of group therapy as a viable therapeutic option for individuals with chronic closed head injury (CHI) within the changing South African context. Penn (1993) has emphasized the unique challenges facing the Speech-Language Therapist (SLT) working with the South African client who may be multilingual and who, historically, may have had limited access to adequate facilities, owing to a variety of sociopolitical, economic and transportation factors.

In the preface to her book, Elman (1999a, p. xiii) stated that "Group therapy is enjoying a renaissance" particularly given the economic constraints within which SLTs find themselves working. Similarly, in South Africa today, people are finding the luxury of individual therapy more and more unaffordable, and group therapy is being advocated as a more cost-effective form of therapy. Another benefit of group therapy in South Africa relates to the reported high client-therapist ratio (Uys \& Hugo, 1997). Given this situation, it is the current writers' contention that group therapy provides a relevant, effective and economic vehicle for providing neurogenic communication treatment. Holland (in Holland \& Ross, 1999 , p. 116) has likewise emphasized her current belief that "individual treatment has become a useful adjunct to group treatment".

Persons with CHI may potentially experience a variety of long-term residual problems that could interfere with their ability to communicate efficiently at home and in the workplace. This may result in a diminished sense of self-esteem and self-worth that ultimately affects their ability to re-enter and remain successfully in the community. Gillis (1999) stated that one of the greatest difficulties faced by the individual with a CHI for resuming a productive and enjoyable lifestyle is poor psychosocial skills. She refers to the longstanding advocacy for group therapy by Ben-Yishay and Prigatano (1990), who believe that group interventions are necessary to address psychosocial needs. Clearly, group treatment may be seen as an ideal vehicle to address the needs of the individual with $\mathrm{CHI}$ owing to its inherent interactive, social and supportive components.

A review of the current literature (Elman, 1999a; Elman \& Bernstein-Ellis, 1999; Gillis, 1999; Holland, 2000; Holland \& Beeson, 1999; Holland \& Ross, 1999) reveals numerous other advantages of group therapy, including the following: A group acts as a microcosm of society (Gillis, 1999; Yalom, cited by Adair Ewing, 1999), creating a safe, non-threatening environment where relevant issues and cognitive-communicative deficits are dealt with. In addition, group therapy promotes interaction and interdependence among 
members, which Adair Ewing (1999) has identified as a crucial component in facilitating much of the progress that takes place by the group members. Furthermore, the group environment provides a wider array of communication partners, and the opportunity to practise a range of pragmatic skills across contexts, thereby facilitating generalization to natural environments. In addition, opportunities are provided for the members to address self-awareness, monitoring, self-regulation, initiation and other important executive skills (Ehrlich \& Sipes, 1985; Elman \& Bernstein-Ellis, 1999; Gillis, 1999; Wilcox \& Davis cited by Elman, 1999b). Daniels-Zide \& Ben-Yishay (2000, p.192) have likewise advocated the concept of a group being an "ordered environment" where increased awareness and acceptance of disabilities facilitates a return to a life that is nevertheless meaningful. Ylvisaker and Feeney's (2000) use of collaborative projects in groups comprising individuals with $\mathrm{CHI}$ has been shown to be effective in assisting these individuals to deal with the diverse challenges following $\mathrm{CHI}$. In addition to the benefits of group collaboration reported by Ylvisaker and Feeney, they note the value of engaging these individuals in group projects as expert contributors.

When further examining the potential benefits of group therapy, Kagan's (1998) concept of increased communicative confidence and participation in life is considered as being centrally important. The sense of empowerment and advocacy generated by group participation has also been acknowledged by Kagan (2001), who in 2000 joined with a number of her colleagues to form the Life Participation Approach to Aphasia (LPAA) Project Group (Chapey et.al., 2000). This group has put together a statement of values that they believe should guide assessment, therapy and research of the individual with aphasia. They advocate the empowerment of the individual to facilitate their more rapid return to active life, thereby reducing the long-term costs for the individual and society. The current writers believe that these values have equal application to intervention with individuals with $\mathrm{CHI}$.

Kagan's work $(1998,2001)$ is closely complimentary to that of Lyon et al. (1997, p. 695) where enhanced communicative competence is considered to result in a restored sense of self, "strengthening a more active, selfdetermined and controlled role in daily life." This thinking ties in with the earlier writings of Prutting (1982) who emphasised the role of one's social identity in relation to one's communicative and linguistic competence. Sarno (1997, p.676) advocated the move towards developing models and methodologies for empowering clients to become "consumers and advocates for themselves." This process has been conceptualised by Sarno (1997, p.676) as improved quality of life for the individual, which she described as "an emerging and important rehabilitation issue." It incorporates parameters such as independence in communication, life status and coping skills.

The above philosophy falls within the Social Disability Model, referred to by Coles and Eales (1999), reflecting a shift away from focusing on the impairment to empowering the disabled individual and their significant others to coping with the restrictions they may face. The World Health Organisation's 1980 classification of consequences of disease has also recently been revised into the ICIDH-2 (1998) (Lux, 1999), now called the International Classification of Functioning, Disability and Health. It sets out three interactive levels of functioning namely: Impairments, Activities and Participations. Group therapy appears to target these levels of functioning with particular emphasis on the latter two levels.

A review of the literature reveals a surprising lack of empirical research into the value and outcomes of group therapy for individuals with CHI. Elman (1999b), Elman and Bernstein-Ellis (1999) and Kearns (1994) have stressed the need for further research to validate group therapy - particularly within the economic climate in which therapists find themselves working today. Garrett (1999) has likewise urged clinicians to develop and standardise useful outcome measurement tools, as well as to report on the changes in communication status for individuals participating in group therapy programs. Furthermore, this attitude reflects the recommendation of the LPAA Project. Group (Chapey et al., 2000) for clinicians to re-define their clinical and research efforts to facilitate the increased life participation of individuals with aphasia. The current writers would like to extend this invitation to the realm of rehabilitating individuals with $\mathrm{CHI}$ within a group context.

Based on the need for further data, this article describes the observations made by the writers of the apparent impact of participation in a conversational group over time for individuals with $\mathrm{CHI}$, together with the group members' and their significant others' perceptions of group therapy.

\section{METHOD}

\section{MAIN AIM OF STUDY}

The main aim of the study was to describe the overall impact of participation in a conversation group (CG) for individuals with chronic $\mathrm{CHI}$ in the Department of Communication Pathology at the University of Pretoria (UP).

\section{Sub-aims of study}

To provide a historical overview of the $\mathrm{CG}$ from 1995-2000, highlighting the different phases through which the group has evolved over this time period.

To describe the changes occurring in the pragmatic skills of each individual subject.

To describe the compilation and application of a QOL Scale examining the subjects and their significant others' perception of the role played by the $\mathrm{CG}$ in quality of life and social-communicative competence. To describe and compare the results reported on the QOL Scale by the subjects and their significant others.

To make recommendations regarding the refinement of the scale that was used in the study.

\section{RESEARCH DESIGN}

In this study, both qualitative and quantitative research data gathering and data analysis procedures were used. Data was gathered and documented qualitatively by means of non-systematic clinical observations over six years since the inception of the $\mathrm{CG}$ 
in 1995. These observations were made annually by the first writer of this paper (who has been involved with the running of the CG since its inception), together with student group facilitators working with the group members for a year at a time. The data from these observations were then examined retrospectively and cumulatively by the current writers.

The administration of a scaled questionnaire reflects the use of a quantitative data collection procedure, as attempts were made to quantify the perceptions of the group members and their significant others with regard to the effects of group therapy. A scale allows for fairly accurate assessment of the beliefs and opinions of individuals as opinions and beliefs are often thought of in terms of graduations (McMillan \& Schumacher, 2001).

\section{HISTORICAL OVERVIEW OF THE CG}

\section{Phases through which the CG has evolved}

The CG for individuals with CHI was established in 1995. Since its inception, the group has functioned as an open group in order to accommodate the movement of members in and out of the group. There has, however, been a core of people who have remained members since its inception and who have ensured its continued development. Thus, although the addition of a new member changes the dynamics of the group, this has not been found to revert the group back to its initial stages of group development.

Each year two final-year SLT students act as group facilitators under the guidance of the first writer of this paper, who was responsible for starting the group in 1995. The group consists of both English and Afrikaans speakers and both languages are spoken interchangeably during the group meetings. The group meets once a week for an hour-and-a-half in the Speech and Hearing Clinic of the UP in a one-way mirror room for student training purposes. Since the Speech and Hearing Clinic is part of the UP, the group runs according to the University timetable.

Data on the group process was gathered by means of non-systematic clinical observation over several years. In retrospect, the application-of Tuckman's framework (cited by Adair Ewing, 1999) for conceptualising the formation and ongoing development of group process is useful. Table 1 reflects the CG's process within this framework from 1995 to 2000 . Tuckman has divided group development intó four useful stages, namely forming, storming, norming and performing. The forming stage usually occurs over the first few sessions. Here introductions are made which set the tone for the future sessions. During the storming stage, agreements and ways of operating within the group are set. It is at this time that conflicts may arise, creating a dynamic in which certain members take the lead and others follow. It is also at this time that individual personalities create the group personality. During the norming stage, rules are used to govern the group, and it is at this stage that the ground rules were established in the CG. The performing stage is characterised by increased cohesiveness and co-operation of the group members as a unit. Members may also be noted to adopt lifelong changes during this final stage.

\section{Group members}

Table 2, displays the demographic features of the CG members, both past and present, since the inception of the group in 1995 until 2000.

Note should be taken that only four of the 21 group members are female. Furthermore, only two of the group members (D \& $\mathrm{T}$ ) had a stroke, while the remaining group members sustained a $\mathrm{CHI}$ at some point over the period 1986 to 2000 . Member D was included in this group since its inception, as he reportedly felt more comfortable in the CG than in the conversation group for individuals with Aphasia (running concurrently in the same Department) which, at the time, comprised mostly elderly women. He has enjoyed the status of "honorary member" of the CG and has been a valuable asset to the group ever since. It is apparent that younger individuals with Aphasia are keen to join the CG for individuals with $\mathrm{CHI}$ rather than the group for individuals with Aphasia, as the former group comprises younger members. For this reason, Member T joined the CG in 2000. Members $\mathrm{T}$ and $\mathrm{D}$ were not included in this study, as the current study was concerned with individuals with CHI only. Table 3, shows the duration of group participation by each member, as well as the reasons for their leaving the group over the time period of 1995 to 2000.

Examination of Tables 2 and 3 reveals the following:

- Over the period of 1995 to 2000 there has been a total of 19 group members with CHI, and two with Aphasia, with an average 6 to 8 group members at any one time. Despite the movement of individual members in and out of the group, it is clear that a core group of members (B, C, \& D) have participated continuously since 1995 .

- The duration of coma ranges from no loss of consciousness to 7 months.

- The education levels at the time of injury ranges from scholar to tertiary-level education. Five of the seven members who have participated in the group for two years or longer were in the process of completing their tertiary education, or had already graduated at the time of their injury.

- Age at joining the group ranges from 20 to 46 years, with an average age of all the members being 27 years. For the individuals with a CHI, the average age was 26 years.

- Duration of group therapy participation ranged from as little as 6 months to 6 years and ongoing.

- Reasons for members leaving the group included: obtaining jobs and starting their own business; returning to full-time studies in another province, or lectures clashing with the group meetings. Other reasons included a lack of motivation to continue participating in the group, a desire to focus on individual therapy as well as Member I's mother deciding that he was not coping in the group.

- Current education and employment status ranged from: five students (only taking one or two subjects per year in order to manage the completion of the degree) to three self-employed group members. Three group members had part-time jobs which appeared to be unstable and constantly changing. Ten of the members were unemployed and are receiving disability pension. 
Table 1. Evolution of the CG functioning based on stages of Tuckman (cited by Adair-Ewing, 1999)

\begin{tabular}{|c|c|c|}
\hline DATE & MEMBERS & GROUP FUNCTIONING \\
\hline 1995 & $\mathrm{~A}, \mathrm{~B}, \mathrm{C} \& \mathrm{D}$ & $\begin{array}{l}\text { Forming stage: Group had pragmatic emphasis. Group sessions structured: focused on } \\
\text { individual cognitive-communicative needs. Themes discussed: organisation \& planning, } \\
\text { decision-making, establishing priorities, developing insight, considering the views of } \\
\text { others \& flexible thinking. Cognitive-communicative functions (e.g. short-term \& long- } \\
\text { term memory) and their management also discussed. Goals established for following } \\
\text { year: paying more attention to social skills, conflict management, self-acceptance \& } \\
\text { acceptance of others, improving self-confidence, \& assertiveness without aggression. } \\
\text { Group thus moving into Storming stage. }\end{array}$ \\
\hline 1996 & B, C, D \& E & $\begin{array}{l}\text { Storming stage: Above-mentioned themes discussed. Additional themes: concepts of } \\
\text { independence, loneliness \& establishment of trust with student facilitators. Meetings } \\
\text { structured \& focused, but group members began moving away from confines of clinic } \\
\text { setting. Regular outings to local coffee shops \& to nearby bird sanctuary. Group } \\
\text { members compiled letters to raise public awareness regarding CHI, which were made } \\
\text { available to hospitals, clinics \& doctors. Poster concerning group therapy made \& was } \\
\text { displayed at local hospitals. }\end{array}$ \\
\hline 1997 & $\begin{array}{l}\text { B, C, D; F, } \\
\text { G, H, I, J \& } \\
\text { K }\end{array}$ & $\begin{array}{l}\text { Storming stage: Needs-assessment implemented. Group members decided on specific } \\
\text { discussion topics, outings into community, \& on format of Open Evening for } \\
\text { dissemination of information to family members \& to public (to become an annual } \\
\text { event). Norming stage: Ground rules (a constitution) established for first time by } \\
\text { members (under guidance of student facilitators) to navigate group activities \& } \\
\text { behaviour throughout year. Ground rules still revised \& updated at beginning of each } \\
\text { year \& include: "freedom to disagree, keeping to a topic, giving each member a chance } \\
\text { to speak, active listening, being sensitive to non-verbal cues, not interrupting \& } \\
\text { monitoring both yourself \& others according to these rules". This fostered foundation of } \\
\text { mutual trust \& respect among group members \& facilitators. Members also planned } \\
\text { visits \& outings, watched thought-provoking videos \& discussed topics established by } \\
\text { needs-assessment. Also decided that new student facilitators taking over group the } \\
\text { following year be introduced to group earlier on to facilitate smoother transition. Goals } \\
\text { \& emphasis shifted from being pragmatically focused within group context, to } \\
\text { empowering group members into becoming confident advocates of CHI within broader } \\
\text { community. This is reflected by formulation of community projects starting in 1997 \& } \\
\text { ongoing, aiming to educate public about CHI. First Open Evening held for family } \\
\text { members and public to share personal experiences \& respective roads to recovery. } \\
\text { Organization \& format of open evening continues to be planned annually during group } \\
\text { meetings. Members given responsibility to prepare for talk, \& to advertise event by e.g. } \\
\text { contacting local press. Increase in cohesiveness \& teamwork in working towards a } \\
\text { common goal reflects Performing stage. }\end{array}$ \\
\hline 1998 & $\mathrm{~F}, \mathrm{I}$, & $\begin{array}{l}\text { Performing stage: Characteristic feature of } 1998 \text { was implementation of community } \\
\text { service project and regular outings. During needs-assessment members expressed need to } \\
\text { move beyond clinic confines into community to disseminate information re. CHI. } \\
\text { Various local high schools visited, raising awareness among adolescent school-going } \\
\text { population regarding causes \& nature of CHI. Group members formulated personalised } \\
\text { speeches about CHI. Another project initiated in } 1998 \text { \& expanded in 1999: working as a } \\
\text { team to compile bilingual information pamphlet (in English \& Afrikaans) about CHI. } \\
\text { Pamphlet made available at schools \& to general public during Open Evening. At end of } \\
\text { 199.8, preliminary self-rating scale developed to determine value of group to members. }\end{array}$ \\
\hline 1999 & $\begin{array}{l}\mathrm{B}, \mathrm{C}, \mathrm{D}, \mathrm{K} \\
\mathrm{L}, \mathrm{M}, \mathrm{N} \& \mathrm{O}\end{array}$ & $\begin{array}{l}\text { Performing stage: Main project: expansion of pamphlet on CHI compiled in 1998. Tips } \\
\text { to facilitate communication with people with CHI during acute \& chronic stages of } \\
\text { recovery were added. Members planned to visit schools (as in 1998). Members benefited } \\
\text { by meeting \& interacting with Headway (support group for individuals with CHI) in } \\
\text { Johannesburg. Self-rating Scale refined into a Quality of Life Scale administered to both } \\
\text { group members and their significant others to determine impact of group on their quality } \\
\text { of life. }\end{array}$ \\
\hline 2000 & $\begin{array}{l}\text { B, C, D, J, } \\
\text { K, M, P, Q, } \\
\text { R, S, T \& U }\end{array}$ & $\begin{array}{l}\text { Performing stage: Group effort to educate public by trying to find sponsorships for } \\
\text { group pamphlet, \& other endeavours e.g. key rings, mugs \& mouse pads for } \\
\text { dissemination of information. No sponsorships found, but learning facilitated. Group } \\
\text { member } J \text { instrumental in co-ordinating formation of National Lobby Group for } \\
\text { individuals with brain injury. Group members shared ideas with him, \& attended launch } \\
\text { of organisation. Outings into community, \& opportunities to practice improved } \\
\text { interpersonal skills. Open Evening more ambitious than before. Group members used } \\
\text { role-playing to share information with general public re living with a CHI. Larger venue } \\
\text { used on University campus with biggest turnout to date. }\end{array}$ \\
\hline
\end{tabular}




\begin{tabular}{|c|c|c|c|c|c|}
\hline Member & $\begin{array}{c}\text { Date of } \\
\text { accident }\end{array}$ & $\begin{array}{l}\text { Duration of } \\
\text { coma }\end{array}$ & $\begin{array}{c}\text { Educational level } \& \\
\text { Employment Status at time of } \\
\text { injury }\end{array}$ & $\begin{array}{l}\text { Age at joining } \\
\text { the group }\end{array}$ & $\begin{array}{c}\text { Current Educational \& Employment } \\
\text { status (2000) }\end{array}$ \\
\hline $\mathrm{A}$ & 1992 & 21 days & Matric & 20 years & Self-employed-"odd jobs". \\
\hline B & 1986 & 7 months & Scholar - Matric. & 26 years & $\begin{array}{l}\text { Full-time Student BA III (Taking one or two subjects } \\
\text { at a time). }\end{array}$ \\
\hline $\mathrm{C}$ & 1992 & 18 days & B Com Student & 26 years & Unemployed. Disability pension. \\
\hline $\mathrm{D}$ & Stroke-1987 & 2-3 days & B.Com Accountancy Financial Manager & 46 years & Unemployed. Disability pension. \\
\hline $\mathrm{E}$ & 1995 & 2 months & Std 8 & 25 years & Self-employed; building machines. \\
\hline $\bar{F}$ & 1996 & 14 days & Std 9, Computer courses & 20 years & $\begin{array}{l}\text { Constantly changing employment in a part- time } \\
\text { assistant-receptionist capacity. }\end{array}$ \\
\hline $\mathrm{G}$ & 1996 & 8 weeks & $\begin{array}{l}\text { Matric. Working on Uncle's farm before } \\
\text { commencing army service. }\end{array}$ & 21 years & Part-time apprentice motor mechanic. \\
\hline $\mathrm{H}$ & 1996 & 4 months & Std 7 and Level 5 at Technical College. & 24 years & Unemployed. Disability pension. \\
\hline $\mathbf{I}$ & 1995 & 1 month & $\begin{array}{l}\text { Technical College. Working as electrician } \\
\text { on a contract basis. }\end{array}$ & 24 years & Unemployed. Disability pension. \\
\hline $\mathbf{J}$ & 1995 & 42 days & MBA & 33 years & $\begin{array}{l}\text { Self-employed. Currently the chairperson of National } \\
\text { Lobby Group for Brain Injury. }\end{array}$ \\
\hline $\bar{K}$ & 1993 & 21 days & $\begin{array}{l}\text { Matric. Computer Programmer in Police } \\
\text { force. }\end{array}$ & 31 years & Unemployed. Disability pension. \\
\hline $\mathbf{L}$ & 1995 & 21 days & B. Eng. (Ind.) & 29 years & Unemployed. Disability pension. \\
\hline $\mathbf{M}$ & 1996 & 21 days & National Higher Diploma & 35 years & Unemployed. Disability pension. \\
\hline $\mathbf{N}$ & 1998 & 21 days & Mechanical Engineering II Student & 21 years & $\begin{array}{l}\text { Full-time student, changing direction of studies to } \\
\text { BA Information Science. }\end{array}$ \\
\hline $\mathrm{O}$ & 1999 & 3 months & BA I Student, Sign Language Course & 20 years & Full-time student, continuing studies. \\
\hline$P$ & 1995 & 12 days & $\begin{array}{l}\text { Matric. } 6 \text { Months of Graphic Design } \\
\text { Diploma. }\end{array}$ & 23 years & Unemployed. Disability pension. \\
\hline $\mathbf{Q}$ & 1988 & $21 / 2$ months & B.A. Psychology III student & 33 years & $\begin{array}{l}\text { Completed Degree Obtained a HED \& currently a } \\
\text { student doing a Diploma in Trauma Debriefing. }\end{array}$ \\
\hline $\mathbf{R}$ & 2000 & 26 days & $\begin{array}{l}\text { Financial information systems at } \\
\text { Technikon. Worked in computer industry. }\end{array}$ & 23 years & Unemployed. Disability pension. \\
\hline$S$ & 1995 & 3 weeks & $\begin{array}{l}\text { BSc (QS). Worked as Quantity Surveyor at } \\
\text { the Post Office. }\end{array}$ & 32 years & $\begin{array}{l}\text { Full-time student, second year correspondence course } \\
\text { in Accountancy at Technikon SA. }\end{array}$ \\
\hline$T$ & Stroke -2000 & $?$ & $\begin{array}{l}\text { Degree in Industrial Psychology, working } \\
\text { full-time for a car-manufacturing company }\end{array}$ & 37 years & Unemployed. Disability pension. \\
\hline $\mathrm{U}$ & 1998 & 6 weeks & B.Com Accountancy 11 student & 23 years & Self-employed. Vending machine business. \\
\hline
\end{tabular}




\begin{tabular}{|c|c|c|c|c|c|c|c|}
\hline Member & \multicolumn{5}{|c|}{ Years of group participation } & \multicolumn{2}{|r|}{ Reason for leaving the group } \\
\hline & 1995 & 1996 & 1997 & 1998 & 1999 & 2000 & \\
\hline A & $\checkmark$ & & & & & & Got engaged and found a job as a sports-trainer. \\
\hline $\bar{B}$ & $\checkmark$ & $\checkmark$ & $\checkmark$ & $\checkmark$ & $\checkmark$ & $\checkmark$ & \\
\hline $\mathrm{C}=$ & $\checkmark$ & $\checkmark$ & $\checkmark$ & $\checkmark$ & $\checkmark$ & $\checkmark$ & \\
\hline $\mathrm{D}$ & $\checkmark$ & $\checkmark$ & $\checkmark$ & $\checkmark$ & $\checkmark$ & $\checkmark$ & \\
\hline $\mathrm{E}$ & & $\begin{array}{c}6 \\
\text { months }\end{array}$ & & & & & Needed individual therapy. \\
\hline $\mathrm{F}$ & & & $\checkmark$ & $\begin{array}{c}6 \\
\text { months }\end{array}$ & & & Left to work full-time as an office assistant. \\
\hline $\mathrm{G}$ & & & $\checkmark$ & & & & Needed to move on and lived far away. \\
\hline $\mathrm{H}$ & & & $\checkmark$ & & & & Lack of motivation. Currently plans to return. \\
\hline I & & & $\begin{array}{c}6 \\
\text { months }\end{array}$ & $\begin{array}{c}6 \\
\text { months }\end{array}$ & & & Mother decided member wasn't coping in the group \\
\hline J. & & & $\checkmark$ & $\checkmark$ & & $\checkmark$ & $\begin{array}{l}\text { Moved on to start own business, but is still in contact with the } \\
\text { group. }\end{array}$ \\
\hline $\mathrm{K}=$ & & & & $\checkmark$ & $\checkmark$ & $\checkmark$ & \\
\hline $\mathrm{L}$ & & & & $\checkmark$ & $\checkmark$ & & No longer motivated. \\
\hline $\mathrm{M}=$ & & & & $\checkmark$ & $\checkmark$ & $\checkmark$ & \\
\hline $\mathrm{N}$ & & & & & $\checkmark$ & & Returned to full-time studies in the Cape. \\
\hline $\mathrm{O}$ & & & & & $\checkmark$ & & $\begin{array}{l}\text { Returned to full-time studies. Felt more competent, and that no } \\
\text { longer belonged in the group. }\end{array}$ \\
\hline $\mathbf{P}$ & & & & & & $\checkmark$ & \\
\hline $\mathrm{Q}$ & & & & & & $\checkmark$ & \\
\hline$\vec{R}$ & & & & & & $\checkmark$ & \\
\hline $\mathrm{S}$ & & & & & & $\checkmark$ & \\
\hline$T$ & & & & & & $\checkmark$ & \\
\hline $\mathrm{U}$ & & & & & & $\checkmark$ & \\
\hline
\end{tabular}

Participation in Conversation Group

Group members who participated in study 


\section{Group goals}

The main goals of the CG had been to improve the group members' pragmatic skills and quality of life by:

- Providing the opportunity for group members to improve, plan, implement and monitor the use of functional, compensatory communication strategies and appropriate conversational rules for the generalization of these skills outside the group setting.

- Facilitating the adjustment to, and acceptance of, functional cognitive-communicative deficits and their impact on interactions with other people.

- Instilling a sense of empowerment within the group members to take responsibility and control of their daily lives, as well as reaching out to the general community to become advocates for individuals with CHI.

\section{DATA COLLECTION}

\section{Subjects}

Only those members who had sustained a $\mathrm{CHI}$ and who have attended the CG for two years or more (Members B, C, J, K, L \& M) were included in this study. Owing to the fact that the Pragmatic Protocol was administered to the group members bi-annually, a minimum period of two years of participation in the group was selected as a cut-off period to ensure that there would be enough data for comparative purposes. The group members who participated in the current study are referred to henceforth as Subjects B, C, J, K, L \& M. The nature of the study was explained to those group members who were selected as subjects, and their verbal agreement to participate in the study was obtained. Assurance was given that their identity would remain anonymous at all times.

\section{Materials for Data Collection}

\section{Pragmatic Protocol (Prutting and Kirchner, 1987)}

The Pragmatic Protocol was selected as a means for data collection as it was designed to be used while observing individuals, engaged in spontaneous conversation during unstructured communicative interactions (Prutting, Kirchner, Hassan \& Buen, 1984 in Binder, 1984). It is a societal appraisal rather than a clinical test, where cognizance is taken of how society will view the individual's communicative behaviour. Thus, a behaviour may be incorrect, but not necessarily judged as inappropriate by society (Prutting in Binder, 1984). The Pragmatic Protocol comprises 30 pragmatic behaviours that are rated as appropriate or inappropriate based on societal perceptions. This pool of behaviour is known to be developed and used appropriately by children entering school, adolescents and adults, and together comprise an individual's communicative and social competence (Binder, 1984). The communicative competence of each group participant was rated as a percentage of the number of appropriate pragmatic behaviours within each of the three pragmatic domains namely: Verbal, Paralinguistic and Non-Verbal.
Quality of Life Scale

The results obtained from the Pragmatic Protocol did not sufficiently reflect the nature and quality of ongoing changes and subjective improvements that were apparent to both the group facilitators and the subjects themselves. Their apparent increased self-esteem and enhanced participation in life (Chapey et. al., 2000; Holland, 2000; Kagan, 2001) needed to be rated more effectively. Schuessler, Fisher \& Draper (cited by Sarno, 1997) have identified the challenges inherent in measuring quality of life since it is not easily observable. Sarno has suggested that of all the measures of quality of life, self-report (including interviews, questionnaires and rating scales) is the most frequently used measurement technique. Given the apparent paucity of suitable scales available to date to assess these apparent quality of life changes, the current writers developed a preliminary Self-Rating Scale in 1998 on which individual subjects could rate dimensions of their quality of life. During 1999 , this was further developed into the Quality of Life (QOL) Scale (Appendix A). This scale emerged from an examination of available literature regarding quality of life measurements (Ehrlich \& Sipes, 1985; Laman \& Lankhorst, 1994; Penn, 1998) and dimensions of the revised classification of the World Health Organization, the ICIDH-2 (Lux, 1999). In addition, personal communication with various authorities including Alant, (1998), Holland, (1998), and Kagan, (1999), assisted in the formulation of the QOL Scale. This QOL Scale was designed to determine the perceived effect of group therapy on the quality of life and social-communicative competence of each subject. A similar scale, namely the QOL Scale: Perception of Significant Other was compiled for the significant others of the subject to complete. The scale was identical to the QOL Scale given to the subjects, with only the wording adapted to target the significant other. While perception is a personal and subjective experience, the current writers decided to include observation of the subjects' significant others in order to gain further information of the subjects' level of functioning beyond the confines of the $C G$ setting.

\section{Description of the QOL Scales}

- Both QOL Scales comprise ten questions and are presented in Appendix A.

- The first and last questions of the QOL Scales are open-ended, requiring the subjects and their significant others to provide reasons why the subjects joined the group, and to describe what the CG has come to mean to them.

- The remaining eight questions require the subjects and their significant others to rate their respective perception of quality of life and various socialcommunicative competencies on a self-anchored rating scale (Fouché, 1998) from 1 to 10 (1-poor, 5average, 10-very good). These competencies include communication skills, self-image, assertiveness and advocacy regarding CHI, participation in every day life, decision-making, overall self-acceptance specifically, as well as acceptance by society generally. In compiling this scale, attempts were made to incorporate the three 
interactive levels of functioning of the ICIDH-2 (1998) (Lux, 1999) - namely Impairments, Activities and Participations. Question 2 reflects the Impairment level; while Questions 4, 5 and 7 examine the Activities level, and Questions 3, 6, 8 and 9 reflect the Participation level.

- The QOL Scale incorporates three time dimensions. The subjects and their significant others were requested to rate their perceptions of quality of life and various social-communicative competencies as they were after the $\mathrm{CHI}$ was sustained (but prior to enrolment with the CG), as they were at the time of completing the QOL Scale, and how they are expected to be with future participation in the $\mathrm{CG}$.

\section{Procedures for Data Collection}

Administration of the Pragmatic Protocol (Prutting \& Kirchner, 1987)

The Pragmatic Protocol has been used by the student facilitators since 1996 to rate the pragmatic skills of each individual subject at the beginning and the end of each year that they attended the group. The Pragmatic Protocols were completed independently of the subjects, and were considered to reflect valid perceptions of the subjects' communicative competence over these two time periods in a year. Each Pragmatic Protocol was examined by the first writer of this article over the entire period (1996 to 2000) to ensure inter-rater reliability. Any differences in ratings between the first writer and the student group facilitators were resolved through discussion. The number of Pragmatic Protocols administered to each subject depended on the year in which they joined the group. Owing to the fact that a minimum of two years' participation in the group was selected as a cut off period for inclusion in this study, each subject in this study had a minimum of four completed Pragmatic Protocols.

\section{Administration of the Quality of Life Scale}

Towards the end of 1999, the QOL Scale was handed to each subject to complete themselves (with the assistance of the group facilitators where necessary). The QOL Scale: Perception of Significant Other was sent home with each subject for their significant other to complete with a cover letter explaining its aim and nature. Each subject was asked to rate their perceptions of their own social-communicative competencies and quality of life as they were before joining the group (after sustaining the $\mathrm{CHI}$ ), currently and into the future with ongoing group participation. Each subject's significant other was likewise asked to rate their perceptions of the family member or friend with a $\mathrm{CHI}$ along the same dimensions.

\section{Procedures for Data Analysis}

\section{Analysis of the Pragmatic Protocol}

The Pragmatic Protocol was examined by converting into percentages, each subject's pragmatic score (obtained for each year that the Pragmatic Protocol was administered) for the three pragmatic domains (namely: Verbal; Paralinguistic and Non-Verbal aspects). Since
Prutting and Kirchner (1987) theoretically divided the Pragmatic Protocol into these three specific domains, it was decided to examine these areas independently as opposed to an overall percentage pragmatic competence. For the purposes of comparison, these results are presented in bar graph format (See Figures 1, 2 and 3).

\section{Analysis of the Quality of Life Scale}

The results of the subject's ratings on the eight scaled questions were totalled, and a score was obtained out of 80 which was then converted into a percentage. This procedure was followed for their ratings over three time periods, namely: before joining the group (after sustaining a CHI), current perceptions and future expectations. The results for each of these three time periods are presented on the same graph for each subject to facilitate comparison of changed perceptions over time. The responses made by the subjects to the two open-ended questions are discussed qualitatively. The same procedure was followed for the scales completed by the significant others. The ratings by the subjects and their significant others are presented on separate bar graphs, but will be discussed with reference to each other (See Figures 4 and 5).

\section{PRAGMATIC PROTOCOL}

\section{Verbal Aspects}

The percentages obtained by each subject for this pragmatic domain are presented in Figure 1.

Examination of Figure 1 shows the improvements made over the years in the verbal domain of pragmatics by four of the six subjects. Closer examination of these results reveal improvements in for example, topic selection and maintenance by Subject $C$; improved repair and revision and topic introduction by Subject $\mathrm{L}$; and fewer interruptions by Subject K. CG therapy addresses verbal pragmatic aspects directly as group members are referred to the ground rules regularly. These ground rules encourage, among others, keeping to the topic, active listening, being sensitive to non-verbal cues and not interrupting. The improvements noted in these four subjects' verbal pragmatic skills may therefore be ascribed to participation in the CG. An explanation for the lack of change in Subject B's verbal pragmatics may be that he had his accident 14 years ago, in contrast to the other subjects whose accidents were more recent. He receeived many years of individual cognitive-based Speech Therapy, and by the time he joined the $\mathrm{CG}$, his verbal skills appear to have reached a plateau. Subject J's verbal pragmatic skills were consistently fully appropriate since he joined the CG.

\section{Paralinguistic Aspects} in Figure 2.

The results of this pragmatic domain are presented

Examination of Figure 2 reveals improveménts in only Subject M, whose paralinguistic skills appeared to improve with increased confidence. On first joining the group, he was very quiet and withdrawn, speaking softly and relatively unintelligibly. Over time, his confidence appeared to grow and with it, a concomitant increase in intelligibility of speech. The overall minimal improvements in the CG subjects' Paralinguistic pragmatic 

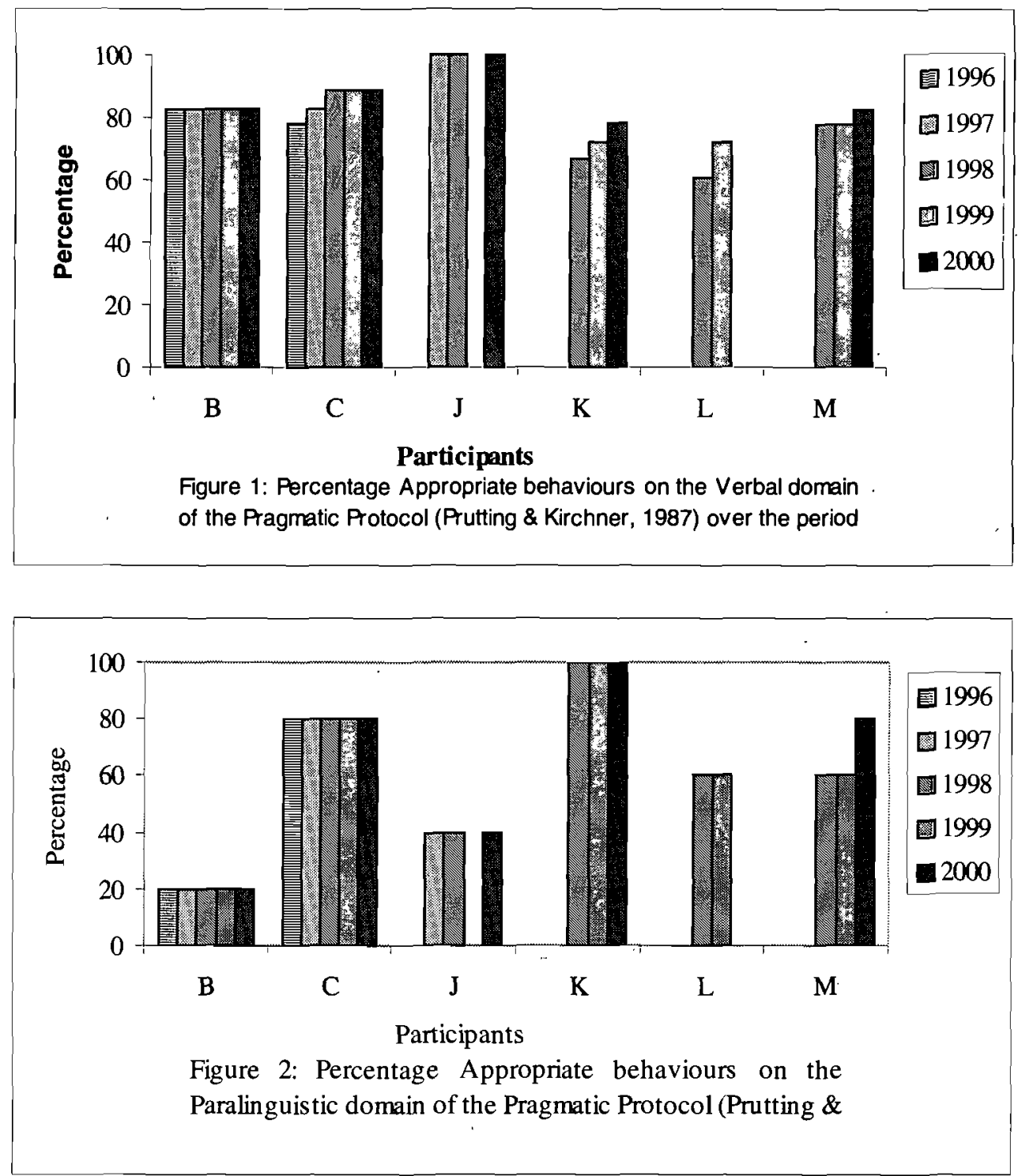

behaviours were not unexpected. Paralinguistic aspects reflect the dysarthric quality of many of the subjects' speéch (in particular, Subjects B, J and L), which have remained stable several years after the $\mathrm{CHI}$ and are not directly addressed in CG therapy (with the exception of occasional reminding for relevant subjects to speak more slowly). It is interesting to note that Subjects B and J (who were the most severely penalised in this pragmatic domain), were rated as the most appropriate in the Verbal pragmatic domain, highlighting the discreteness of the three pragmatic domains defined on the Pragmatic Protocol. (See Figure 1).

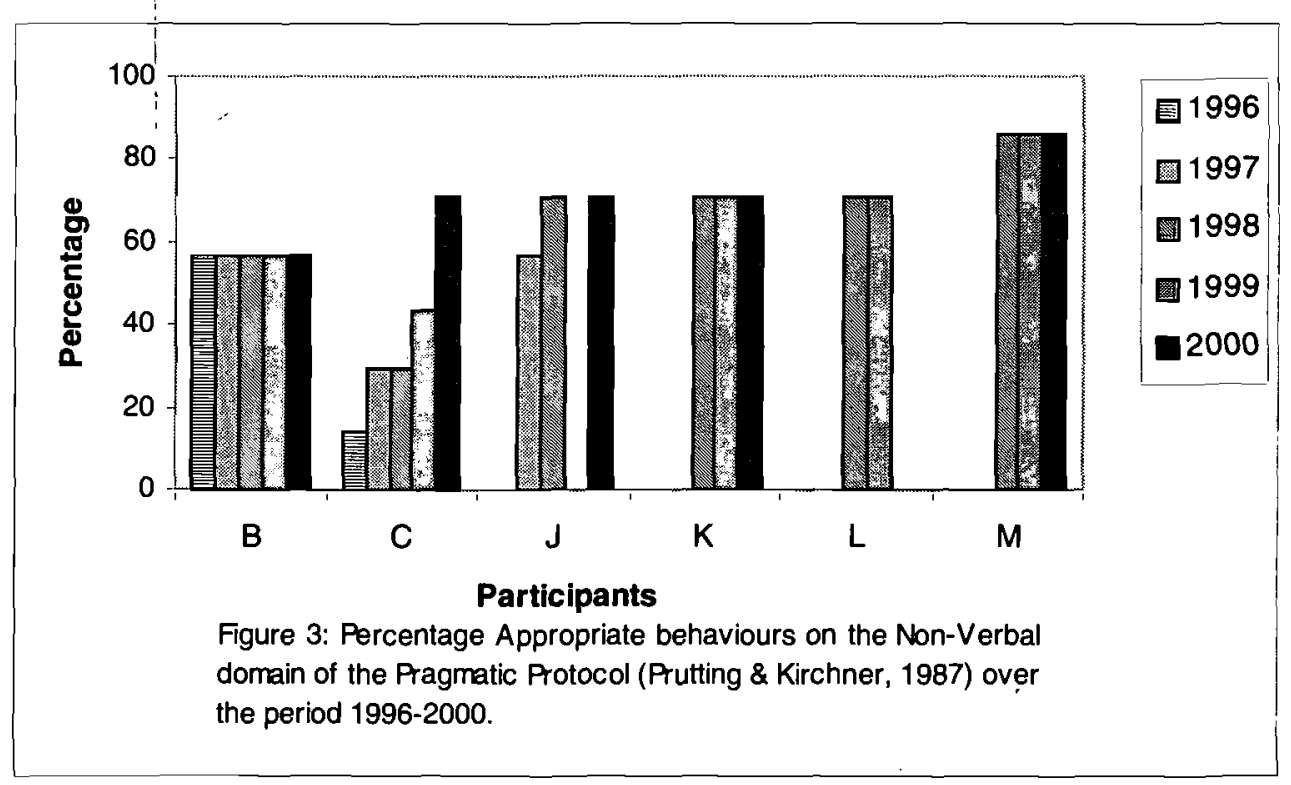


Non-Verbal pragmatic behaviours may potentially powerfully intrude upon ones' perceived communicative competence. CG therapy is able to address selected nonverbal aspects such as physical proximity, physical contact, facial expression and eye gaze. Other non-verbal behaviours such as body posture, foot/leg and hand/arm movements and facial expression may reflect physical injuries sustained during the accident and may therefore be resistant or potentially more complicated to change. This may explain the limited overall improvement noted in the subjects' non-verbal domains. Examination of Figure 3 reveals that only selective gains were made by two of the subjects whose non-verbal pragmatic behaviours were specifically addressed within the CG context. For example, Subject C's attention was drawn to improving eye gaze, facial expression and physical proximity. He responded well, and in so doing, became a more appropriate conversational partner.

In summary, the above-described results of the Pragmatic Protocol reflect the emphasis placed on certain pragmatic aspects within CG therapy. Because CG therapy inherently focuses on the interactive, conversational and social components; more attention is placed on verbal aspects, with attention to Non-Verbal and Paralinguistic aspects only where relevant. This may explain why more improvements were noted in the Verbal pragmatic domain, than in the Paralinguistic and Non-Verbal domains. Given the limited overall improvements reflected by the Pragmatic Protocol, the group facilitators felt that these results did not sufficiently reflect the subjective improvements that were apparent in the form of improved self-confidence, and the desire to become advocates for individuals with brain injury generally. For example, Subjects $\mathbf{B}$ and $\mathbf{J}$ showed no and little pragmatic improvement respectively. Despite this, they were the two CG subjects who demonstrated the most notable leadership and advocacy qualities. Subject B regularly contacts the press about a range of issues related to public education and brain injury. Subject $\mathbf{J}$ has played a major role in the formation of a National Lobby Group for individuals with Brain Injury. These observations confirmed the need to develop the QOL Scale as another means of documenting the changes noted in individuals with $\mathrm{CHI}$ participating in group therapy over time.

\section{QUALITY OF LIFE SCALE}

Results of Subjects' Rated Questions

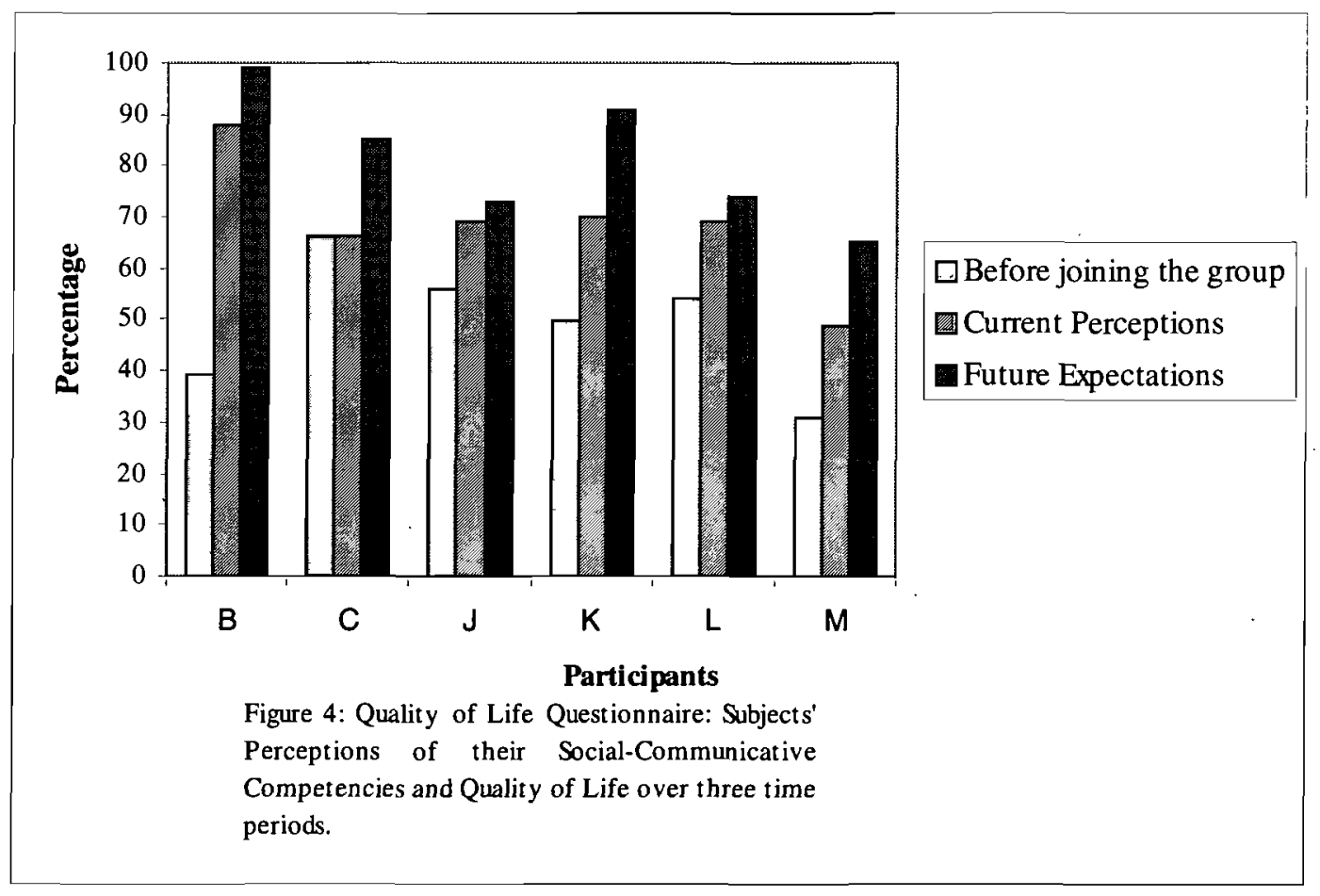

Examination of Figure 4 above reveals that all subjects, with the exception of Subject C, showed that they perceived consistent improvements of their own performance on parameters of quality of life and socialcommunicative competencies (including self-esteem, assertiveness, increased life participation, and advocacy) from before joining the group, to present level of functioning. For example, Subject B indicated a $50 \%$ improvement in his quality of life and socialcommunicative competencies from before joining the CG to the present. This subjective feeling of wellbeing may have motivated him to have sufficient confidence to become an advocate for individuals with brain injury. In contrast to the other CG subjects, Subject $\mathrm{C}$ does not feel that he has benefited from CG therapy. Despite this, he has continued to attend CG Therapy since its inception in 1995, and has indicated that he believes he will benefit from ongoing participation in the CG. His predictions that he will benefit from future participation (despite his current perception of not having improved since joining the group) may be due to the social and interactive components of the group. Alternatively, he may be optimistic that he may ultimately benefit from the ongoing changes and concomitant challenges that take place in the group format and structure from year to year. Brown, Gordon and Haddad (2000) maintained that quality of life resides solely in the target person's judgement and feelings. Given this, the most important implication of Subject C's results is that he anticipates improved social-communicative skills 
and quality of life with continued participation in the group.

It is interesting to note that Subject $J$ (who is considered by the current writers to be functioning at a higher cognitive level than the other subjects) rated his quality of life and social-communicative competencies as lower as compared with the other subjects. This may reveal that awareness and insight into his deficits may have made him more self-critical. Talbot and Giroux (2000) has likewise noted that individuals with milder $\mathrm{CHI}$ rated their quality of life poorer than those with more severe $\mathrm{CHI}$. In addition, examination of Subject J's performance on the Pragmatic Protocol reveals that he was severely penalized on the Paralinguistic domain, reflecting the dysarthric component of his speech. His sensitivity to listener's reactions and penalty when he talks may well be reflected in his lower ratings of his quality of life and socialcommunicative competencies.

In summary, in contrast to the minimal pragmatic gains made by the subjects, the improvements noted, on the ratings on the QOL Scale were considered to highlight the subjective value of the group process in facilitating improved perceived quality of life for the subjects in the CG. Examination of the raw data show that all questions were rated with equal importance by the subjects, and that no question was identified as being worthy of a more extreme rating. This may imply that not one particular dimension of quality of life and social-communicative competence on the scale used was being targeted by the CG. Rather, it would appear that each of these dimensions is perceived as being equally addressed within the group context. Furthermore, these findings validate the enhanced self-esteem and advocacy noted by the writers in the individual subjects of the CG over time. The writers are encouraged by these results, because. even though the subjects may no longer be making dramatic improvements and are living with the "sticky residuals" (Holland, 2000, p.8) of CHI, ultimately the personal experience of feeling confident and competent enough to participate more actively in daily life implies benefit gained from ongoing participation in group therapy.

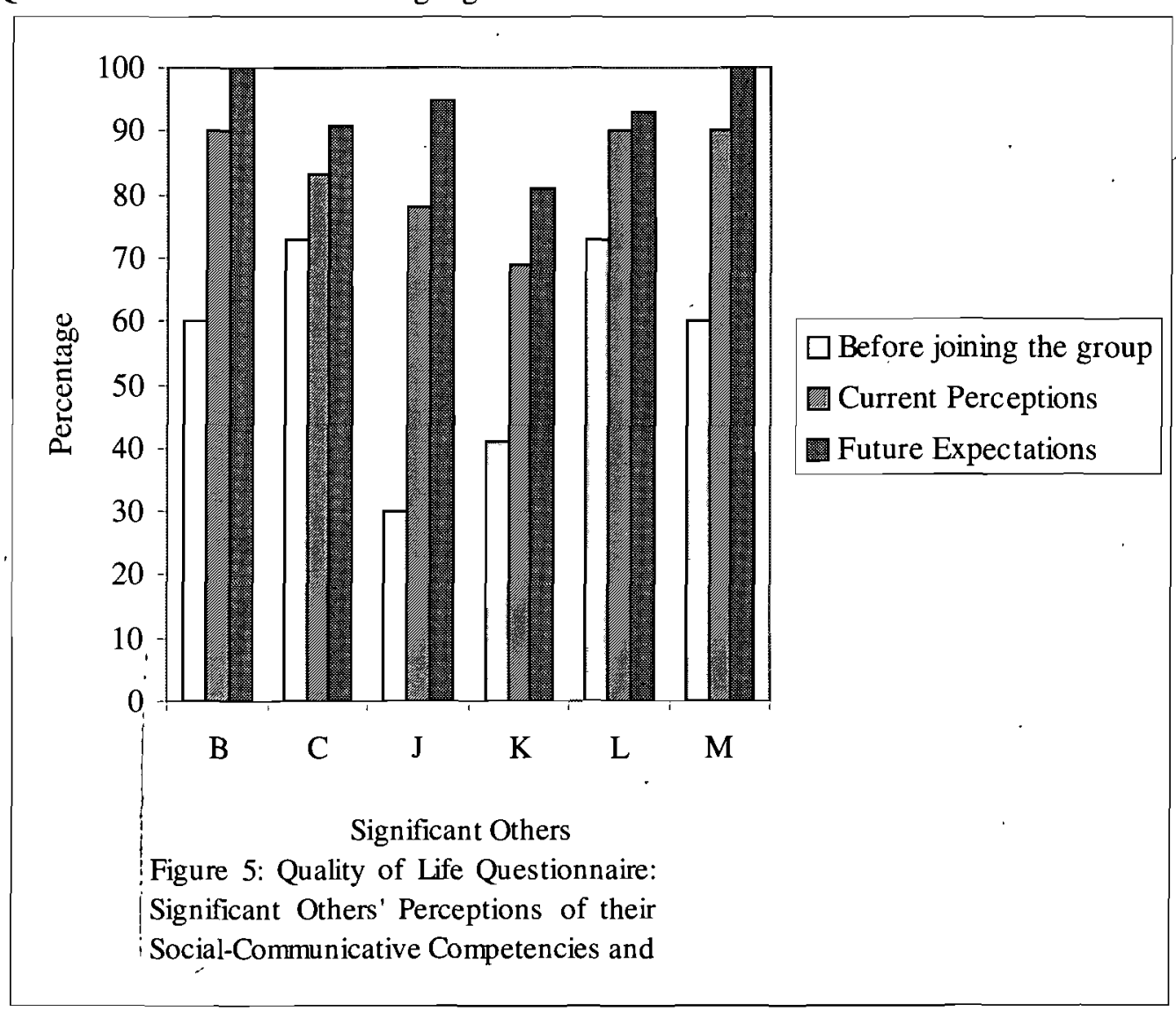

\section{Results of Significant Others' Rated Questions}

Examination of Figure 5 reveals an overall optimistic trend in the significant others' perceptions of their family member's social-communicative competence and quality of life. As with the positive ratings made by the subjects, the writers find these results encouraging. Even though significant others are not able to rate how the subject perceives his own quality of life, they are able to observe improvements in confidence, self-image and participation by the subject in daily life. The results therefore imply that the significant others attributed the positive changes noted in the subjects to, among others, participation in the CG. In addition, their anticipation of future improvements indicates that they are supportive of ongoing group participation. Of particular interest is the rating made by Subject J's significant other who noted a $48 \%$ increase in her perception of Subject J's social-communicative skills and quality of life from before joining the group to the time of completing the scale. This supports the writers' observations of the increase in Subject J's confidence to become a strong advocate for individuals with brain injury in South Africa.

Comparison of Figures 4 and 5 shows that all the significant others (with the exception of Subject K's significant other) rated the current and anticipated future level of social-communicative competence and quality of life as being higher than the subjects did themselves. This may reflect the ongoing hope by the significant other for 
their family member to continue to improve. It should however be noted that in this study, the significant other was not controlled for, and ranged from a parent to a sibling to a spouse. The ratings for Subject $\mathrm{K}$ were made by his wife, who has subsequently divorced him. Her lower ratings may have been confounded by many other negative sentiments about him.

\section{Results of Subjects' Open-Ended Questions}

When examining the first open-ended question, namely "Why did you join the group?" the following trends were apparent:

- Subjects wanted to meet other individuals with CHI.

- They wanted to find help in dealing with problems associated with $\mathrm{CHI}$ in a supportive and stimulating environment.

- They wanted to use the group to assist with longterm planning.

Examination of the second open-ended question, namely "What have you gained from the group?" revealed the following trends:

- Improved self-acceptance and feeling more accepted by others.

- Improved self-confidence.

- Improved social and interpersonal skills.

- Improved conversational skills.

These trends highlight the subjects' focus on themselves and their interpersonal skills, with little reference to extending themselves for readiness to go out in the "real world" and independently re-enter life and the workplace. Most of the subjects reportedly joined the group to socialise with individuals with the same kinds of difficulties, to find support and to gain confidence. The emphasis appeared to be on requiring a more informal, social environment, rather than a structured therapeutic group.

Despite the apparent absence of improved advocacy, many of the subjects had been noted, by the writers to have become more empowered and confident via their increased active participation in the planning and implementation of events, such as talking to school children and the annual Open Evening. Certain subjects had also begun corresponding via e-mail in an ongoing way with organizations, newspapers, peers and high profile personalities both nationally and internationally, in their effort to educate and inform the public about CHI. A few of the subjects have been interviewed on radio programmes and in the newspapers where their stories and perceptions were shared. Subject J has played a seminal role in the establishment of a National Lobby Group for individuals with brain injury in South Africa, and this project has become an all-consuming commitment for him.

\section{Results of Significant Others' Open-ended Questions}

When examining the first open-ended question, namely "Why do you think your friend/family member joined the group?" the following trends were apparent:

- To find the opportunity to socialise and find support from other individuals with $\mathrm{CHI}$.

- To improve communication skills.

- To improve self-confidence.
While these above-mentioned trends in the significant others' written replies highlight their recognition of the supportive and social aspects of the group, they do not indicate their frequently-verbalised anxieties concerning the ability of the subjects to ultimately be able to return to independent life and work.

Examination of the second open-ended question, namely "What do you feel he/she has gained from participating in the group?" revealed the following trends:

- Improved self-confidence and motivation.

- Improved communication skills.

- Improved assertiveness.

- Improved insight into their problems.

- Improved empathy with others.

The above trends highlight the significant others' perceiving the group as being therapeutic and supportive in function, resulting in improved insight and selfconfidence.

\section{CONCLUSION}

Overall, the above-described findings lend support to Holland (2000; 2001) and Holland and Ross's (1999) reference to the inherent power of groups, reflected in the subjects' perceptions of improved quality of life including increased self-confidence, assertiveness, acceptance and overall life participation. Closer examination of the data revealed that despite the overall benefits of group participation, nine members left the group over time for various personal and practical reasons. This finding validates the clinical observation that in addition to these reasons, groups are understandably not for every individual with CHI. Reservations and resistance to participating could include factors such as: the desire to "feel normal" and no longer be associated with a disability group; goals not perceived as addressing individual cognitive-communicative needs; and not feeling comfortable sharing and disclosing in a group context.

The results from repeated administration of the Pragmatic Protocol over time revealed only' slight pragmatic improvements. Despite the plateauing of pragmatic competence, the inherent magic and power (Holland \& Ross, 1999) within the CG appeared to reveal itself in the reported improvements in the quality of life dimensions and social-communicative competence by the subjects and their significant others. Thus, when attempting to reliably measure and report on group changes over time, the Pragmatic Protocol needs to be supplemented by other scales that reliably measure dimensions of quality of life. Garrett (1999) has likewise advocated the need to develop and standardise a range of tests to be used by therapists working with participants in long-term outpatient group settings such as Universities. These tests need to cover the range of therapeutic goals focused on in the groups, and should be re-administered over time in order to record the perceived ongoing changes.

The importance of subjective perceptions, and their value in filling the gaps by tráditional measures has been acknowledged by various authors (Brown et al., 2000; Whiteneck, 1994) thus supporting the need for developing and using subjective measures and quality of 
life scales in our clinical interventions. The QOL Scale used in the present study was a pilot scale that needs to be refined and validated to assist in gaining more data into the perceived benefits by members participating in this kind of conversation group. Broadly, recommendations for improvements to this scale could include refinements of the ratings and the questions posed to the group members to more conclusively tap into the insider experience of CHI. More specifically, suggested improvements on questions related to the group experience could include, for example: "What, if anything, have you gained from the group?" and "Do you have any suggestions for changing or improving the group? If so, please describe."

In addition to the above findings, group therapy examined over a period of 2 years or longer, is clearly an evolving process. With reference to Tuckman's 4 stages of group development (cited by Adair Ewing, 1999) (namely: forming; storming; norming and performing), the current writers believe that group therapy at the performing stage evolves further through different phases that may be conceptualised as a continuum seen in the representation below:

\section{PHASE 1 \\ PRAGMATIC EMPHASIS \\ PHASE 2 \\ PHASE 3 \\ QUALITY OF LIFE EMPHASIS \\ RE-ENTRY TO LIFE \& WORK}

The shift from Phase 2 to Phase 3 is crucial to ensure that the group moves out of its "comfort zone", and the members extend themselves (within their limitations) to developing the skills that will be realistically required to function independently and successfully "out there" as they attempt to gain gainful employment and more successful life participation. (Chapey et. al., 2000; Kagan, 2001). Ylvisaker (2000) and Ylvisaker and Feeneys' (2000) concept of collaborative group participation in meaningful projects, where expert roles are created for the members are suggested as useful goals in the later stages of therapy for individuals with CHI. In addition, group therapy would need to focus on assisting the members and their significant others to develop more realistic insight into their residual deficits and strengths, thereby preventing failure as they endeavour to participate more actively in the "real world." As BenYishay (2000, p.130) has noted, this is the phase where, "in spite of achieving less than a full return to one's preinjury abilities after rehabilitation, life is meaningful" as the individual finds value in being a growing and contributing human being.

In conclusion, group therapy constitutes a challenge for both the therapist and the group members, a process that has been well acknowledged by Adair Ewing (1999). Group therapy is not simply an extension of individual therapy, but requires the members' commitment to fully participating and sharing. In the process, the resulting benefits will include, among others a sense of empowerment, a sense of greater control over their own lives with a concomitant increase in personal self-esteem (Holland, 2000; 2001 \& Ylvisaker, 2000). The current writers believe that given the perceived benefits of participating in a conversational group for individuals with $\mathrm{CHI}$, together with its concomitant economic viability, more groups should be established in the diverse range of settings in which therapists work (particularly within the South African context). Outcomes data should be gathered on an ongoing basis in order to make the process of group therapy more accountable, so that our understanding of the nature of these benefits can be better defined.

\section{ACKNOWLEDGEMENTS}

This study would not have been possible without all the members of the $\mathrm{CG}$, past and present, who were willing to share the courageous manner in which they are living their lives. The current writers would also like to sincerely thank Professor Erna Alant, (Centre for Augmentative and Alternative Communication, UP) for her continuing support and belief in the value of the CG. We are extremely grateful to both her, and Professor Audrey Holland (Department of Speech and Hearing Sciences, University of Arizona) for their ongoing constructive input regarding this article.

\section{REFERENCES}

Adair Ewing, S.E. (1999). Group process, group dynamics, and group techniques with neurogenic communication disorders. In R.J. Elman (Ed.); Group treatment of neurogenic communication disorders: The expert clinician's approach. Boston: Butterworth-Heinemann.

Alant, E. (1998). Personal communication, Centre for Augmentative and Alternative Communication, University of Pretoria, South Africa.

Ben-Yishay, Y., \& Prigatano, G. (1990). Cognitive remediation. In M. Rosenthal, E.R. Griffith \& J.D. Miller (Eds.) Rehabilitation of adult and child with traumatic brain injury. Philadelphia: F.A. Davis.

Ben-Yishay, Y. (2000). Postacute neuropsychological rehabilitation: A holistic perspective. In A.L. Christensen, \& D. Uzzell (Eds.) International handbook of neuropsychological rehabilitation. New York: Kluwer Academic.

Binder, G. M. (1984). Aphasia: A societal and clinical appraisal of pragmatic and linguistic behaviours. Masters dissertation, University of California, Santa Barbara.

Brown, M., Gordon, W.A., \& Haddad, L. (2000). Models for predicting subjective quality of life in individuals with traumatic brain injury. Brain Injury, 14 (1), 5-19.

Campbell-Korves, M. (1991). Special issues for a person with a head injury. In J. Williams, T. Kay (Eds.) Head injury: A family matter. Baltimore: Paul H. Brookes.

Chapey, R., Duchan, J., Elman, R., Gracia, L., Kagan, A., Lyon, J., \& Simmons Mackie, N. (2000). Life participation approach to aphasia: A statement of values for the future. ASHA Leader, 5(3), 4-7. 
Coles, R., \& Eales, C. (1999). The aphasia self-help movement in Britain: A challenge and an opportunity. In R.J. Elman (Ed.) Group treatment of neurogenic communication disorders: The expert clinician's approach. Boston: Butterworth-Heinemann.

Daniels-Zide, E., \& Ben-Yishay, Y. (2000). Therapeutic milieu day program. In A.L. Christensen, D. Uzzell (Eds.) International handbook of neuropsychological rehabilitation. New York: Kluwer Academic.

Ehrlich, J.S., \& Sipes, A.L. (1985). Group treatment of communication skills for head trauma patients. Cognitive Rehabilitation, 3, 32-37.

Elman, R.J., \& Bernstein-Ellis, E. (1999). The efficacy of group communication treatment in adults with chronic aphasia. Journal of Speech, Language and Hearing Research, 42(2), 411- 419.

Elman, R.J. (Ed.).(1999a). Group treatment of neurogenic communication disorders: The expert clinician's approach. Boston: ButterworthHeinemann.

Elman, R.J. (1999b). Introduction to group treatment of neurogenic communication disorders. In R.J. Elman (Ed.). Group treatment of neurogenic communication disorders: The expert clinician's approach. Boston: Butterworth-Heinemann.

Fouché, C.B. (1998). Data collection methods. In A.S. de Vos (Ed.). Research at grass roots: A primer for the caring professions. Pretoria:Van Schaik.

Garrett, K.L. (1999). Measuring outcomes of group therapy. In R.J. Elman (Ed.). Group treatment of neurogenic communication disorders: The expert clinician's approach. Boston: ButterworthHeinemann.

Gillis, R.J. (1999). Traumatic brain injury: Cognitivecommunicative needs and early intervention. In R.J. Elman (Ed.). Group treatment of neurogenic communication disorders: The expert clinician's approach. Boston: Butterworth-Heinemann.

Holland, A.L. (2000). Self-determination and selfadvocacy: New concepts for aphasic individuals and their partners. In L. Conner, \& L. Obler, (Eds.), Neurobehaviour of language and cognition. Boston: Kluwer Academic.

Holland, A.L., \& Beeson, P.M. (1999). Aphasia groups: The Arizona experience. In R.J. Elman (Ed.), Group treatment of neurogenic communication disorders: The expert clinician's approach. Boston: Butterworth-Heinemann:

Holland, A.L., \& Ross, R. (1999). The power of aphasia groups. In R.J. Elman (Ed), Group treatment of neurogenic communication disorders: The expert clinician's approach. Boston: ButterworthHeinemann.

Kagan, A. (1998). Supported conversations for adults with aphasia: Methods and resources for training conversation partners. Aphasiology, 2(9), 816 - 830 .

-Kagan, A. (2001). Supported conversation for adults with aphasia. Workshop presented in the Division of Communication Sciences and Disorders, University of Cape Town.

Kearns, K. (1994). Group therapy for aphasia: Theoretical and practical considerations. In R. Chapey (Ed.), Language Intervention Strategies in
Adult Aphasia ( $3^{\text {rd }}$ Edition). Baltimore: Williams \& Wilkins.

Laman, H., \& Lankhorst, G. J. (1994). Subjective weighting of disability: An approach to quality of life assessment in rehabilitation. Disability and Rehabilitation, 16(4), 198-204.

Lux, J.B. (1999). Towards a common language for functioning and disablement: ICIDH-2 (The International Classification of Impairments, Activities and Participation). Special Interest Division 2 Neurophysiology and Neurogenic Speech and Language Disorders, 9(1), 8-10.

Lyon, J.G., Cariski, D., Keisler, L., Rosenbek, J., Levine, R., Kumpula, J., Ryff, C., Coyne, S., \& Blanc, M. (1997). Communication partners: Enhancing participation in life and communication for adults with aphasia in natural settings. Aphasiology, 11(7), 693-708.

McMillan, J.H., \& Schumacher, S. (2001). Research in education: A conceptual introduction. New York: Addison Wesley Longman, Inc.

Penn, C. (1993). Aphasia therapy in South Africa: Some pragmatic and personal perspectives. In A. L. Holland, \& M.M. Forbes, (Eds.), Aphasia treatment: World perspectives. California: Singular Publishing Group.

Penn, C. (1998). Clinician-researcher dilemmas: Comment on "Supported conversations for adults with aphasia". Aphasiology, 12(9), 839-844.

Prutting, C.A. (1982). Pragmatics as social competence. Journal of Speech and Hearing Disorders, 47, 123134.

Prutting, C.A., \& Kirchner, D.M. (1987). A clinical appraisal of the pragmatic aspects of language. Journal of Speech and Hearing Disorders, 52, 105119.

Sarno, M.T. (1997). Quality of life in aphasia in the first post-stroke year. Aphasiology, 11(7), 665-679.

Schurink, E.M. (1998). Participatory Action Research as a tool for sustainable social development and reconstruction. In A.S. de Vos (Ed.), Research at grass roots: A primer for the caring professions. Pretoria:Van Schaik.

Talbot, L., \& Giroux, F. (2000). Quality of life perception of head-injured persons: From hospital to community. Brain and Cognition, 44, 39-42.

Uys, I., \& Hugo, R. (1997). Speech-language pathology and audiology: Transformation in teaching, research and service delivery. Health SA Gesondheid, 2(2), 2329.

Whiteneck, G. G. (1994). Measuring what matters: Rehabilitation outcomes. The $44^{\text {th }}$ Annual John Stanley Coulter Lecture. Archives of Physical Medical Rehabilitation, 75, 1073-1076.

Ylvisaker, M. (2000). Personal Communicátion. Associate Professor, College of Saint Rose, Albany, New York.

Ylvisaker, M. \& Feeney, J. (2000). The project approach in brain injury rehabilitation: Theory and illustrations. Mini-seminar presented at the American Speech, Language and Hearing Association Annual Convention, Washington, D. C. 


\section{APPENDIX A:}

\section{OUALITY OF LIFE SCALE}

\section{Scale of self-perception by the group member with a $\mathrm{CHI}$}

G. Goldblum, M. Mulder \& A. von Gruenewaldt (1999)

1. Why did you join the group?

2. How do you rate your communication skills (on a scale of 1-10) as you think they

a) * were before joining the group

b) o are now

c) 1 will improve with further participation in the group?

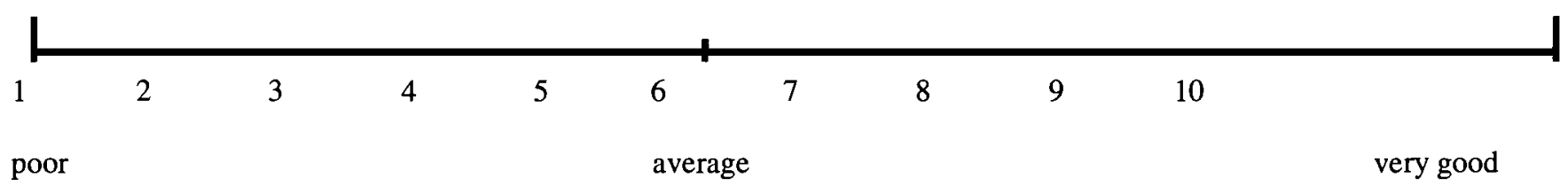

3. How do you rate your self-image as you think it ...

a) * was before joining the group

b) 0 is now

c) 1 will improve with further participation in the group?

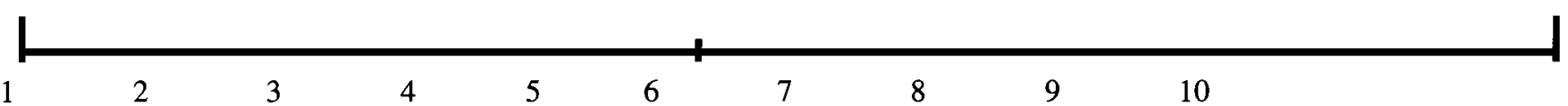

poor average very good

4. How do you rate your ability to stand up for what you believe in ...

a) * before joining the group

b) o as you see it now

c) 1 to improve with further participation in the group?

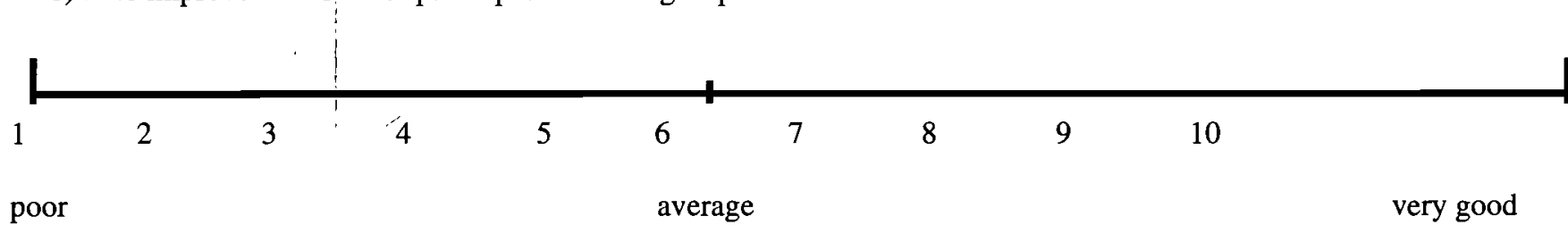

5. How do you rate your ability to convey information about $\mathbf{C H I}$ to others ...

a) * before joining the group

b) 0 as you see it now

c) 1 to improve with further participation in the group?

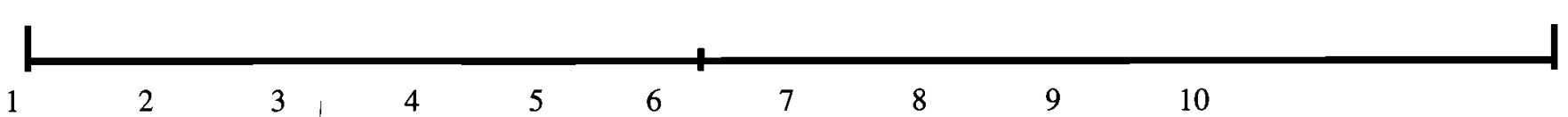


6. How do you rate your ability to participate in everyday activities, conversations and discussions ...

a) * before joining the group

b) $\circ$ as you see it now

c) 1 to improve with further participation in the group?

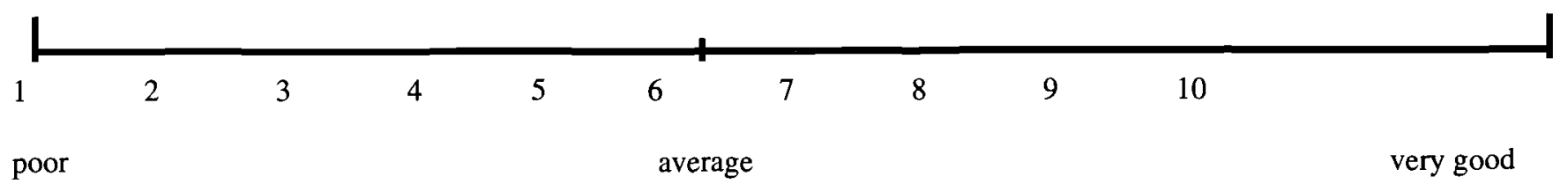

7. How do you rate your ability to make important decisions for yourself and your family ...

a) * before joining the group

b) 0 as you see it now

c) 1 to improve with further participation in the group?

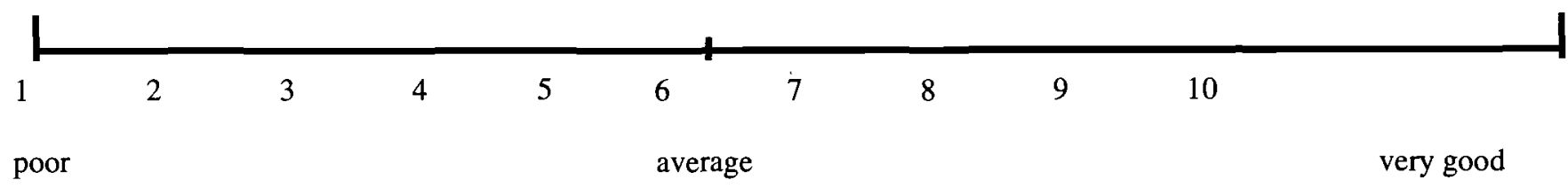

8. Rate your acceptance by society ...

a) * before joining the group

b) $\circ$ now

c) 1 after further participation in the group?

\begin{tabular}{|llllllllllll}
\hline \\
poor
\end{tabular}

9. How OK do you feel with yourself ...

a) * before joining the group

b) $\circ$ now

c) 1 after further participation in the group?

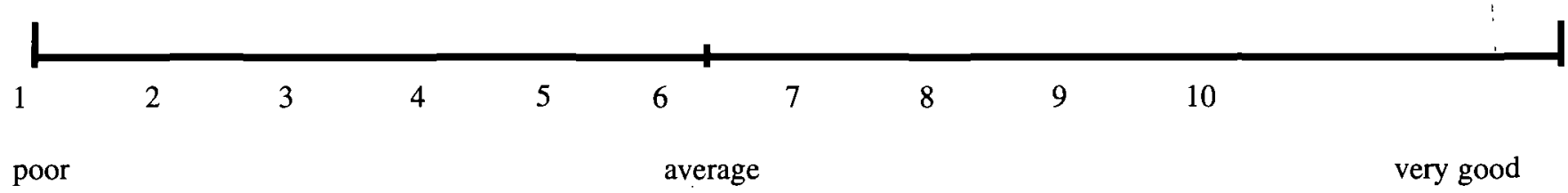

10. What have you gained from the group? 


\section{QUALITY OF LIFE SCALE}

Scale of perceptions of the group member by his/her significant other

G. Goldblum, M. Mulder \& A. von Gruenewaldt (1999)

1. Why do you think your friend/family member joined the group?

2. How do you rate his/her communication skills (on a scale of 1-10) as you think they
a) * were before joining the group
b) $\circ$ are now
c) 1 will improve with further participation in the group?

\begin{tabular}{llllllllllll}
\hline \\
1
\end{tabular}

3. How do you rate his/her rate self-image as you think it ...

a) * was before joining the group

b) $\circ$ is now

c) 1 will improve with further participation in the group?

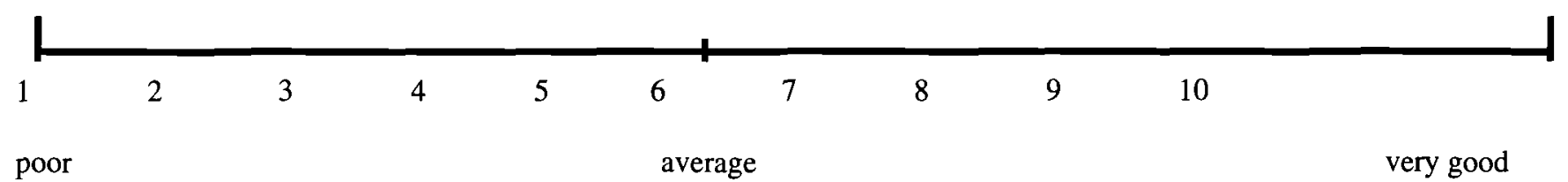

4. How do you rate his/her ability to stand up for what he/she believes in ...

a) * before joining the group

b) o as you see it now

c) 1 to improve with further participation in the group?

\begin{tabular}{|c|c|c|c|c|c|c|c|c|c|c|}
\hline 1 & 2 & 3 & 4 & 5 & 6 & 7 & 8 & 9 & 10 & \\
\hline poor & & & & & & & & & & very good \\
\hline
\end{tabular}

5. How do you rate his/her ability to convey information about CHI to others...

a) * before joining the group

b) o as you see it now

c) 1 to improve with further participation in the group?

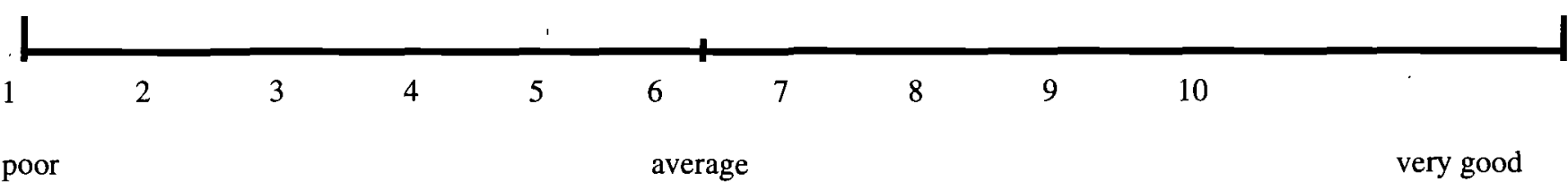


6. How do you rate his/her ability to participate in everyday activities, conversations and discussions ...
a) * before joining the group
b) $\circ$ as you see it now
c) 1 to improve with further participation in the group?

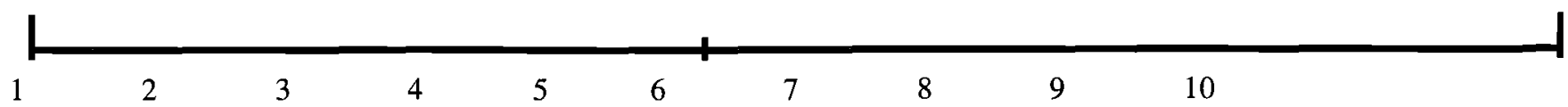

poor

average

very good

7. How do you rate his/her ability to make important decisions for himself/ herself and the family ...

a) * before joining the group

b) 0 as you see it now

c) 1 to improve with further participation in the group?

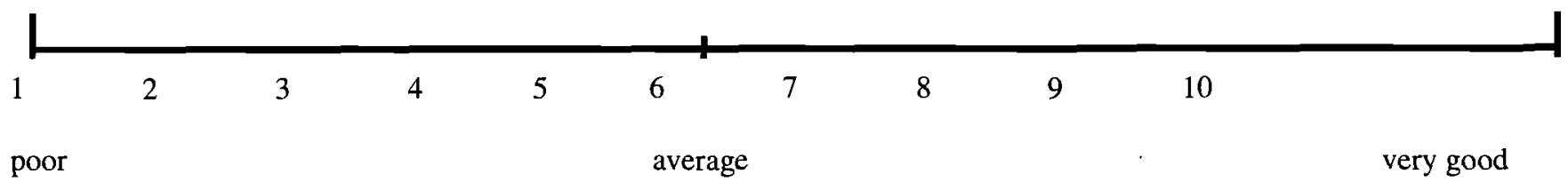

8. Rate his/her acceptance by society ...
a) * before joining the group
b) o now
c) 1 after further participation in the group?

\begin{tabular}{|lllllllllll}
\hline \\
1
\end{tabular}

9. How OK do you think he/she feels with himself/herself ...
a) * before joining the group
b) $\circ$ now
c) 1 after further participation in the group?

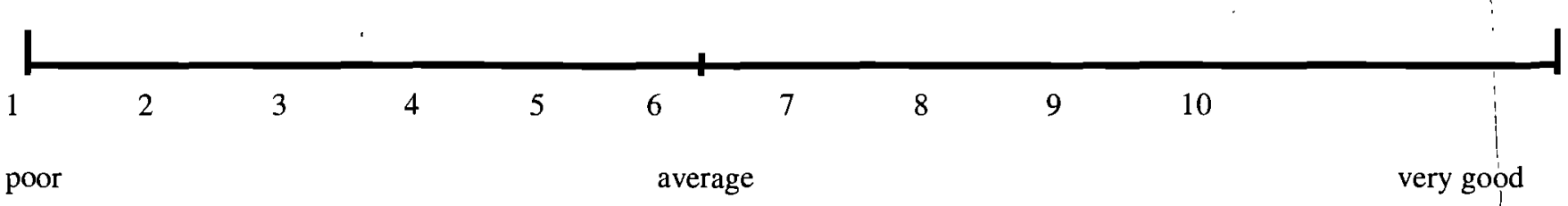

10. What do you feel he/she has gained from participating in the group? 